\title{
Australian Land Use Policy and Planning: The Challenges
}

\author{
Richard Thackway
}

\section{Key Points}

- Land use decisions made during the early years of European settlement are evident in today's broad land use patterns; the location of major population centres; issues of land degradation; patterns of remnant vegetation; and responses to vulnerable, threatened and rare species. This creates issues and challenges that require national coordination and the development of land use strategies.

- In areas that have been cleared for agriculture (primarily cereal cropping) and grazing on improved pastures, remnant areas of native vegetation provide a much-reduced, but vitally important, reservoir for biodiversity.

- In cleared landscapes, issues of soil salinity and acidification create ongoing challenges for governments and industry bodies faced with developing agricultural land use policies and sustainable management systems.

- To avoid perverse planning and land use outcomes, policymakers and land planners need access to nationally consistent, high-quality and up-to-date scientific information and scenario tools. 


\section{Australia's Land Use Policy and Planning}

Australia comprises a land area of almost 7.7 million square kilometres, and was settled and developed between 1788 and 1950—a process that displaced its Indigenous peoples. The contrast between European culture and Indigenous cultures resulted in major ecological and social transformations across the continent, while the establishment of settled agricultural practices resulted in major transformations of the landscape and the fragmentation and modification of native vegetation (Thackway $\&$ Lesslie, 2008). Australia has experienced the world's highest rate of extinctions of mammalian fauna, and parallel losses of biodiversity across many of its ecosystems (Steffen et al., 2009).

Living with the threat of droughts, floods and wildfires of devastating proportions, land managers and developers of land use policy and plans have adapted and learned new systems of agriculture over time. For those from more predictable European origins, learning to understand and adapt to new-world patterns of long-term climate variability was difficult. Arguably, today's decision-makers are generally more aware of, and attuned to, El Niño and La Niña events, which are a natural part of the global climate system, than previously. Across our agro-climatic regions, La Niña events are often associated with higher-than-average rainfall, and are triggers for bumper crops and outbreaks of pest animals and plantsthe antecedents for fuel build-up and major wildfires. El Niño events are associated with prolonged periods of below-average rainfall and, at times, devastating droughts. The rapid onset of a La Niña event, following a severe El Niño event, has been associated with major soil erosion events.

Historically, issues of low soil fertility, and low and highly variable rainfall across most of the hinterland, presented major challenges for governments and land managers, as these problems were unknown in European experience. Land use decisions made during the early years of European settlement continue to reverberate today. They are evident in land use patterns; the location of major population centres; issues of land degradation; patterns of remnant vegetation; and responses to vulnerable, threatened and rare species.

Australia is a federation of eight states and territories. Under the Australian Constitution, each jurisdiction has responsibility for land use policy and planning. As with many areas of national natural resource management (NRM), including land use policy and planning, the Australian Government plays a major role or takes the lead in developing partnerships 
between key national, state and regional stakeholders; establishing and fostering the adoption of national standards and protocols for collecting consistent national datasets; compiling data and information for national and international monitoring and reporting; coordinating cross-border NRM initiatives at a range of spatial and temporal scales; and fostering participation in the development of cross-border land use policies and planning to improve decision-making across space and time.

Almost 64 per cent of Australia's land is being used to meet domestic food and fibre needs, and to provide export income. Less than 4 per cent of Australia's total land area is under intensive agricultural and urban use; in general, native vegetation has been completely removed from such areas. About 2 per cent of the country is used for production forestry, including plantations. Around 57 per cent of the land area has been modified for agricultural and pastoral use, with the bulk of this area being used for livestock grazing on natural pastures. Only 10 per cent of Australia's landmass has been converted from native vegetation to intensive agricultural production, including modified pastures. In areas that have been cleared for agriculture (primarily cereal cropping) and grazing on improved pastures, remnant areas of native vegetation provide a much-reduced, but vitally important, reservoir for biodiversity. In these cleared landscapes, issues of soil salinity and acidification create ongoing challenges for governments and industry bodies faced with developing agricultural land use policies and sustainable management systems.

In 2015, Australia's population was almost 24 million. Five major state capitals, each with a population greater than 1 million, were home to more than 14 million people. These cities-Perth, Sydney, Melbourne, Brisbane and Adelaide - are located in the coastal margin of the southwest, southern and eastern states. Only around 2 million people occupy Australia's interior-much of which is semi-arid and arid rangelands. Such pronounced clustering of people in the coastal zone and immediate hinterland, and across several jurisdictions, creates issues and challenges that require national coordination and the development of land use strategies.

The population of Australia has doubled since 1970. Since the 1950s, Australia's population has transitioned from rural communities to urban and peri-urban dwellers. The bulk of Australia's population is distributed predominantly within 100 kilometres of its coastline. This growth has placed pressure on the coastal zone and its hinterland to provide more land for urban and peri-urban dwellers. Increasing population growth and the pressure to provide access to land for urban and peri-urban 
development in the coastal zone are perennial problems for decisionmakers involved in land use policy and planning. Issues for planning include the conversion of agricultural land use to urban and peri-urban areas. Along with the demand for suitable urban land, there are demands to plan for and provide more open space in urban areas to make cities more liveable. Additionally, a steady demand for access to potable water, clean air, nature-based tourism and conservation reserves (inside and outside) for the protection of biodiversity has accompanied the burgeoning growth of urban and semi-urban areas. To avoid perverse outcomes, policymakers and land planners need access to nationally consistent, high-quality and up-to-date scientific information and scenario tools.

Historically, Australia's economy has been based on developing, servicing and exporting its natural resources, including agricultural and forest products and minerals. In some cases, developing these resources has seen major tension and conflict between those in favour of development and those seeking conservation and protection of natural landscapes. Essentially, these issues involve trade-offs between various aesthetic, social, economic and environmental values. Land use policies and planning transform landscapes, affecting the long-term mosaics of unmodified, modified, removed and replaced vegetation ecosystems. In turn, land use policies, planning instruments and decisions affect the viability of landscapes to generate publicly acceptable mixes of ecosystem services, including clean air, healthy crops, clean water, and parks and reserves for the protection of nature and recreation. Again, such key issues require coordinated national land use policies and initiatives.

In 2015, nearly 37 per cent of Australia's land was in national parks, nature reserves and other protected areas. Such areas, in which the effects of land use on the environment are limited or negligible, contribute to biodiversity conservation objectives. However, despite being little affected by (or in advanced recovery from) clearing, the impact of fire and feral animals can be significant. A commitment by all Australian governments, including states and territories, over almost 20 years is responsible for the relatively large area designated for reserve and off-reserve protection of biodiversity. Regrettably, this coordinated national approach largely ceased in 2010, when the Australian Government withdrew resources from the process.

In 2015, Australia was recognised as having one of the highest gross domestic products in the world. In terms of its natural landscapes and clean and green food production systems, it was also recognised as one 
of the most liveable countries. However, this development has come at a cost, as Australia also has one of the highest carbon dioxide emissions per head of population of any nation.

While Australia's world ranking for natural landscapes, clean and green food production systems and standard of living is high, there are serious problems at the national level in terms of land use policy, including:

- poor coordination and support for NRM, conservation and land use planning

- limited active and current awareness of recent land use decisions, resulting in unforeseen consequences and poor NRM outcomes

- poor awareness and use of nationally consistent, well-maintained information systems developed to support policy and planning at the multiple scales at which decisions are made - that is, national, state, regional, local and non-spatial decision loci, such as issue or sectoral (these information systems are not widely used: why?).

This book is the product of a symposium on land use policy and planning that was held at the Crawford School of Public Policy, The Australian National University, in June 2015. The aims of the symposium were twofold: to review advances in approaches to assessing and mapping land use, ecological condition and related ecosystem services; and to consider how this information could be better generated, managed and used to improve policy and decision-making. Given the magnitude of these aims, we decided to bring key decision-makers in land use policy and planning together with academic researchers and practitioners. All speakers were leaders in their field; they were selected for their capacity to inform and improve the quality of national land use planning and to limit the effects of perverse outcomes in the following areas:

- conversion of prime agricultural land to urban and mining

- loss of biodiversity and natural heritage values

- purchasing water rights at the expense of healthy regional communities and moving agriculture north

- planning for the expansion of regional growth centres and planning for the water needs of large cities in 2050

- planning for the expansion of major cities and urban centres

- planning for a sustainable agricultural sector. 


\section{Some Caveats}

We are acutely aware that only a small subset of people with expertise in land use policy and planning participated in our June 2015 meeting; an even smaller number contributed a chapter to this book. Consequently, we acknowledge that there will be perspectives that are not represented, either in part or in full, in this volume. In many respects, this is positive, for it means that there is more to be said and written about land use policy and planning, and how information and tools can be better generated, managed and used to improve policy and decision-making. If this book stimulates additional dialogue that fosters support for better informed land use policy and planning, we believe that the exercise will have been a valuable one.

\section{References}

Steffen W., Burbidge A., Hughes L., Kitching R., Lindenmayer D., Musgrave W., ... Werner P. (2009). Australia's biodiversity and climate change: A strategic assessment of the vulnerability of Australia's biodiversity to climate change. A report to the Natural Resource Management Ministerial Council commissioned by the Australian Government, CSIRO Publishing. Retrieved from www.climatechange.gov.au/sites/ climatechange/files/documents/042013/biodiversity-vulnerabilityassessment.pdf

Thackway, R. \& Lesslie, R. (2008). Describing and mapping humaninduced vegetation change in the Australian landscape. Environmental Management 42, 572-90. doi.org/10.1007/s00267-008-9131-5 
This text is taken from Land Use in Australia: Past, Present and Future, edited by Richard Thackway, published 2018 by ANU eView, The Australian National University, Canberra, Australia.

doi.org/10.22459/LUA.02.2018.01 